\title{
Health and growth of veal calves provided a fatty acid supplement and a dry teat
}

\author{
L. L. Deikun, ${ }^{1,2} \odot$ G. G. Habing, ${ }^{2} \odot$ J. D. Quigley, ${ }^{1} \odot$ and K. L. Proudfoot $^{2 *} \odot$ \\ ${ }^{1}$ Provimi, Cargill Animal Nutrition, Brookville, $\mathrm{OH} 45309$ \\ ${ }^{2}$ Veterinary Preventive Medicine, College of Veterinary Medicine, The Ohio State University, Columbus 43210
}

\begin{abstract}
Veal calves are at a high risk of disease early in life, which can lead to poor growth. Research is needed to determine interventions that can reduce disease and promote the growth of veal calves. The aim of this study was to determine the effects of fatty acid supplementation and the provision of a dry teat on the incidence of bovine respiratory disease (BRD), navel inflammation, and diarrhea, as well as calf growth. Upon arrival to a commercial veal facility (d 0), 240 Holstein bull calves from 2 cohorts were randomly assigned to 4 treatments using a $2 \times 2$ factorial arrangement $(\mathrm{n}=$ 60/treatment): (1) milk replacer (MR) without fatty acid supplementation and without access to a dry teat (control), (2) MR with fatty acid supplementation (NeoTec5g, Provimi, Brookville, $\mathrm{OH}$ ) and without access to a dry teat (FAS), (3) MR without fatty acid supplementation and with access to a dry teat (TT), or (4) MR with fatty acid supplementation and with access to a dry teat (FAS+TT). Calves were housed in individual pens from 0 to $9 \mathrm{wk}$ and then paired by treatment at wk 9. Milk replacer was fed twice daily using a stepup program. Fatty acid supplement was added to milk replacer at a feeding rate of $0.5 \mathrm{~g} / \mathrm{kg}$ of body weight per head per day for the FAS and FAS+TT groups. Health exams were conducted twice weekly for $6 \mathrm{wk}$ to diagnose BRD, navel inflammation, and diarrhea. Body weight, body condition score (BCS), and structural measurements were recorded at wk 0,5 , and 10 . Average daily gain (ADG) was calculated for wk 1 to 5 , wk 5 to 10 , and wk 1 to 10 . Health data were analyzed using logistic regression and are reported as relative risk. Body weight, BCS, and structural measurements were analyzed using repeated-measures ANOVA, and ADG was analyzed using a generalized linear model. There was no effect of FAS, TT, or their interaction on body weight or BCS. There was no effect of FAS
\end{abstract}

Received July 10, 2019.

Accepted January 8, 2020.

*Corresponding author: proudfoot.18@osu.edu on ADG wk 1 to 5 , wk 5 to 10 , or wk 1 to 10 . There was a tendency for TT to decrease ADG from wk 1 to 5 but not from wk 5 to 10 or wk 1 to 10 . There was a tendency for the interaction of FAS and TT to decrease ADG for wk 1 to 5 but not for wk 5 to 10 and wk 1 to 10. There was no effect of FAS, TT, or their interaction on the risk of $\mathrm{BRD}$, diarrhea, or navel inflammation. We saw no effect of our interventions on calf health or growth. More research is needed to determine whether other factors, such as failure of passive transfer, poor ventilation, barren housing, and low milk allowance in the first few weeks after arrival, may have affected the efficacy of our interventions.

Key words: bovine respiratory disease, diarrhea, navel inflammation

\section{INTRODUCTION}

In the United States, the majority of veal calves are raised to 16 to $20 \mathrm{wk}$ of age and fed both milk replacer (MR) and solid feed before slaughter. Before being transported to a veal growing facility, male calves are born on dairy farms and are usually sold at auction within the first week of life. Calves often arrive to the growing facility in poor condition (Bähler et al., 2012; Pempek et al., 2017; Renaud et al., 2018a) and are at high risk for disease early in life (Wilson et al., 2000; Pempek et al., 2018). Research is needed to determine interventions that reduce disease risk and improve growth in this vulnerable population of animals.

Major health challenges in the veal industry include bovine respiratory disease (BRD), diarrhea, and navel inflammation. Epidemiological research in Europe (Brscic et al., 2011, 2012; Bähler et al., 2012; Pardon et al., 2012, 2013, 2015) and North America (Pempek et al., 2017; Renaud et al., 2018a,b,c) has reported a high prevalence of these diseases as well as risk factors associated with each. For example, calves that arrive to the grower with failure of passive transfer (FPT) are at higher risk of BRD compared with calves that do not have FPT (Pardon et al., 2015). Calves that arrive to the growing facility at a lower BW have also been found 
to be at higher risk of BRD (Brscic et al., 2012). Less experimental work has been done to identify effective interventions to reduce disease risk in veal calves at both the home dairy (e.g., colostrum management and transportation to the auction house) and the grower.

A potential intervention that may reduce disease risk is fatty acid supplementation (Hill et al., 2007a,b, 2011a,b, 2016). For example, a specific combination of functional fatty acids supplemented in MR has been shown to improve antibody titers and growth as well as reduce diarrhea in veal and dairy calves (Hill et al., 2011b; Esselburn et al., 2013; NeoTec4, Provimi, Brookville, $\mathrm{OH})$. Authors suggest that rather than increasing energy alone, specific fatty acids in the supplement, including butyric and linolenic acids, reduce the inflammatory response, improve adaptive immunity, and increase feed efficiency in calves. To our knowledge, no research has assessed the efficacy of fatty acid supplementation to reduce the incidence of disease and improve growth in veal calves. Moreover, no work to our knowledge using veal or dairy calves has assessed the effect of fatty acid supplementation on clinical disease risk other than diarrhea (e.g., BRD or navel inflammation).

In veal barns, calves are commonly housed individually and in relatively barren environments with little to no opportunity to display natural behaviors. Sucking is one of the strongest motivated behaviors in young calves, as their survival is dependent on their ability to drink milk from their dam in nature (de Passillé, 2001). However, in artificial environments such as veal growing facilities, calves lack an outlet for this sucking behavior, such as a bottle or a dry teat, and may perform nonnutritive suckling behavior such as cross-sucking (sucking on another calf) or nibbling (mouthing pen fixtures). Several studies using both dairy calves and veal calves determined that the lack of appropriate environments for calves can increase stress (Rushen and de Passillé, 1995; de Passillé et al., 1997; de Passillé, 2001; Veissier et al., 2002), which may contribute to reduced growth and disease. In addition, suckling and nibbling on pen fixtures may increase pathogen exposure, further affecting the calf's risk of illness. However, to our knowledge no research has determined whether the provision of a dry teat affects a calf's risk of illness or their growth rate.

The objectives of this study were to determine the effects of fatty acid supplementation and the provision of a dry teat on BRD, diarrhea, and navel inflammation in veal calves to 6 wk of age as well as growth to 10 wk of age. We expected that the calves that were fed supplemental fatty acids and provided a dry teat would have the lowest risk of disease and the greatest growth rate. We expected our treatments to affect health and growth of calves due to physiological benefits of the fatty acids (immunity and digestion) and a reduction in stress and exposure to environmental pathogens associated with the provision of the dry teat.

\section{MATERIALS AND METHODS}

The experiment took place at one commercial veal facility in Wooster, Ohio, between June 2017 and October 2017. Calves were cared for according to protocol no. 2017A00000046, which was approved by the Ohio State University's Institutional Animal Care and Use Committee before the start of the experiment.

\section{Animals, Housing, and Feeding}

A total of 240 male Holstein calves were enrolled in the study. Calves arrived to a commercial veal growing facility in Ohio in 2 cohorts of 120 calves each approximately 5 wk apart. Calves were within approximately 1 wk of life on the day of arrival (exact age was unknown) and were originally purchased at auction facilities in the northeastern United States. Calves were enrolled in the study on the day of arrival (d 0). Calves were transported from the auction facility to the growing facility on a 2-floor trailer with naturally ventilated sides and sawdust bedding. The exact transportation route, total time in transit, and whether calves were fed milk, MR, water, or electrolytes before arrival were unknown.

Upon arrival to the growing facility, calves were moved into 1 of 2 rooms in a mechanically ventilated barn (1 cohort/room). On the day of arrival, all calves were provided $2 \mathrm{~L}$ of an oral electrolyte solution in an open bucket. Calves were vaccinated with $2 \mathrm{~cm}^{3}$ of intranasal Inforce 3 (infectious bovine rhinotracheitis, parainfluenza-3, and bovine respiratory syncytial virus; Zoetis Inc., Parsippany, NJ) within $24 \mathrm{~h}$ of arrival. Calves were housed in individual stalls $(2.13 \mathrm{~m} \times 0.61$ $\mathrm{m})$ from the day of arrival until 9 wk of age. Stalls were constructed with wood and Tenderfoot (Tandem Products Inc., Minneapolis, MN), a plastisol-coated woven wire with rectangular openings. Each pen was divided into 2 stalls using removable partitions. The horizontal plastic bars of the partition provided visual access to other calves but limited physical interaction. Each calf had nose-to-nose contact only with his pen mate. At approximately 9 wk of age, dividers were removed to pair adjacent calves.

Throughout the study, calves were fed MR twice daily in an open bucket at approximately 0500 and $1700 \mathrm{~h}$. On the day of arrival (d 0), calves were offered $220 \mathrm{~g}$ of MR powder reconstituted in warm water to create 1.47 
$\mathrm{kg}$ of MR/calf per feeding $(2.94 \mathrm{~kg} / \mathrm{d})$. The MR feeding was gradually increased to $709 \mathrm{~g}$ of MR powder reconstituted to yield $4.99 \mathrm{~kg}$ of $\mathrm{MR} /$ calf per feeding (9.98 $\mathrm{kg} / \mathrm{d}$ ) at $10 \mathrm{wk}$ (the last week of the study). Calves were offered a starter feed comprising corn, chopped straw, and a complete pellet starting on d 1 after arrival in a trough shared by each pair. Water was provided in each individual pen through a metal nipple.

Serum concentration of IgG was determined by serial radial immunodiffusion (Kent Laboratories Inc., Bellingham, WA) on d 1 after arrival. Blood was collected by jugular venipuncture, and serum was separated by centrifugation at $3,000 \times g$ for $15 \mathrm{~min}$ at $4^{\circ} \mathrm{C}$ and frozen at $-80^{\circ} \mathrm{C}$ until assayed. The assay was performed according to the manufacturer's instructions. Serum was thawed overnight, and serum samples were vortexed for $5 \mathrm{~s}$ immediately before delivering $5 \mu \mathrm{L}$ to each well. The radial immunodiffusion plates were incubated overnight at room temperature. The Mancini technique (Mancini et al., 1965) was used to calculate serum IgG, as the diameter of the precipitin rings were measured between 18 and $24 \mathrm{~h}$ after plating. Calves were considered to have FPT when serum concentrations were $<10 \mathrm{~g}$ of $\operatorname{IgG} / \mathrm{L}$.

\section{Treatments and Experimental Design}

To assess the effects of 2 factors (access to a dry teat and provision of a fatty acid supplement), pairs of calves were randomly assigned to 1 of 4 treatments in a $2 \times 2$ factorial arrangement on the day of arrival (d 0): (1) MR without fatty acid supplementation and without access to a dry teat (control), (2) MR with fatty acid supplementation (NeoTec5g, Provimi) and without access to a dry teat (FAS), (3) MR without fatty acid supplementation and with access to a dry teat (TT), or (4) MR with fatty acid supplementation and with access to a dry teat (FAS+TT). The fatty acid supplement contained a blend of functional fatty acids, including butyric, lauric, myristic, palmitic, and linolenic acids.

To reduce any effect of barn location on our outcome measures, the treatments were distributed evenly across the barn; every fourth pair of pens was assigned the same treatment before calves arrived to the growing facility. To randomly distribute calves to treatments, calves were alternately assigned to a pen and treatment as they came off the truck from the auction facility.

For calves in treatments that included the fatty acid supplement, the supplement was mixed in the MR from d 1 until $10 \mathrm{wk}$ after arrival. The fatty acid supplement was fed at a rate of $0.5 \mathrm{~g} / \mathrm{kg}$ of BW per calf per day; the supplement increased weekly (from $22 \mathrm{~g} /$ calf per day at wk 1 to $47 \mathrm{~g} /$ calf per day at wk 10) and was calculated using expected growth rates based on MR intake and BW previously measured at this facility (Pempek et al., 2018). To distribute the fatty acid supplement to only half of the calves, the MR was first mixed for all calves as normal and fed to calves enrolled in treatments without the supplement (control and TT). The fatty acid supplement was then added to the MR and fed to the remaining calves (FAS and FAS+TT). For calves enrolled in the treatments with a dry teat (TT and FAS+TT), teats were mounted to the front of each pen between the open milk bucket and the feed trough.

\section{Health Measurements}

Health exams were conducted twice weekly for $6 \mathrm{wk}$ for each calf by 3 trained technicians. We chose to measure disease twice weekly based on recommendations by McGuirk (2008) and McGuirk and Peek (2014). To ensure good interobserver consistency in health scoring, all 3 technicians were trained by the herd veterinarian before the experiment. During each health exam, calves were screened for signs of $\mathrm{BRD}$, diarrhea, and navel inflammation. A diagnosis of BRD was determined using the University of California, Davis, scoring system (Love et al., 2014, 2016), which assigns weighted point values to each of the following symptoms: head or ear tilt ( 5 points), ocular discharge ( 2 points), nasal discharge (4 points), spontaneous coughing (2 points), rapid or difficult breathing using visual assessment (2 points), and rectal temperature $>39.1^{\circ} \mathrm{C}$ (2 points). For any cumulative score $\geq 5$, the calf was considered to have BRD. Fecal consistency was recorded using a 4-point scoring system adapted from McGuirk (2008; 0 $=$ normal, firm, fully formed; 1 = semi-formed, pasty; 2 $=$ loose, stays on top of slatted floor; 3 = watery, falls through slatted floor; Figure 1). A calf was considered to have diarrhea if they had a fecal consistency score $>2$. Navel inflammation was recorded using a 4-point scoring system adapted from Fecteau et al. (1997; 0 $=$ normal, pencil-sized; $1=$ mildly inflamed, approximately the width of the pointer finger; $2=$ moderately inflamed, approximately the width of the pointer and middle fingers; $3=$ severely inflamed, approximately the width of the pointer, middle, and ring fingers). A calf was considered to have navel inflammation if they had a navel score $>2$. Mortalities were recorded by the farm staff; data were collected on all calves until the day they died.

\section{Growth Measurements}

On wk 0 (d 1), wk 5, and wk 10 after arrival, each calf was weighed and the following body measurements were taken: hip height, hip width, heart girth, 


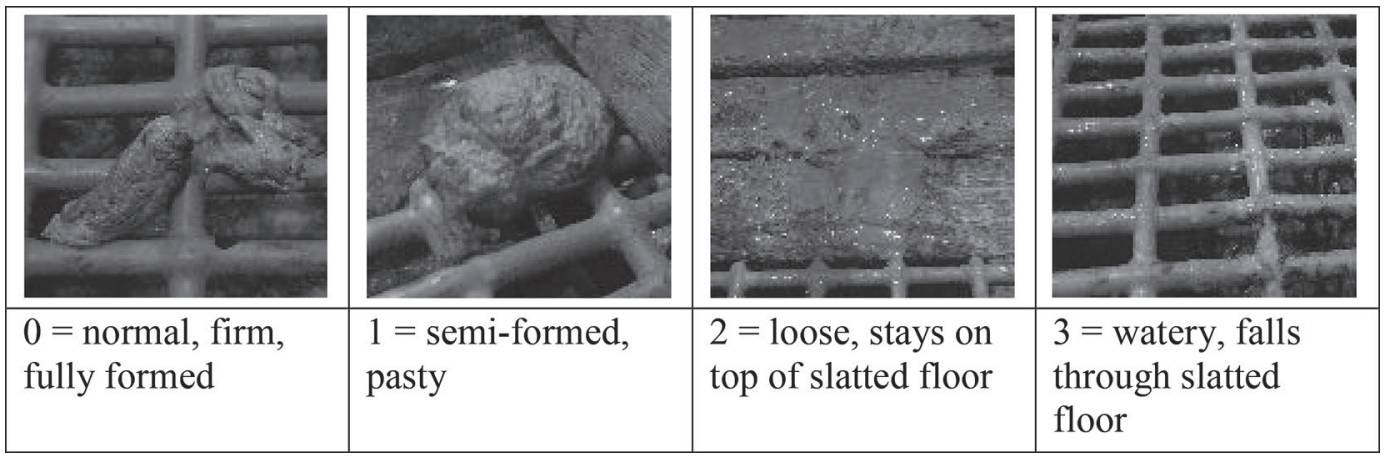

Figure 1. Fecal consistency scoring system (adapted from McGuirk, 2008) used for veal calves housed on slatted floors.

paunch girth, and BCS (5-point scale using 0.25-point increments, where $1=$ emaciated and $5=$ obese; Wildman et al., 1982). Heart girth and paunch girth were measured using a flexible tape measure, hip width was measured using a 24-inch $(60.9-\mathrm{cm})$ trigger clamp and yard stick, and hip height was measured using a slidingscale height stick with a bubble level.

\section{Statistical Analysis}

All statistical tests were performed using SAS software (version 9.4; SAS Institute Inc., Cary, NC). Continuous data were assessed for normality using PROC UNIVARIATE in SAS, and the distribution of model residuals was visually assessed for normality. The unit of analysis for growth measurements (BW, structural measurements, BCS, and ADG) was the pair, as the last measurement (wk 10) was taken after the calves were paired. Thus, all measurements of growth were first averaged across the pair before analysis. The unit of analysis for disease (navel inflammation, diarrhea, and BRD) was the calf, as all measurements were taken before calves were paired. Despite the randomization procedures, serum concentrations of IgG differed between treatments; calves enrolled in the FAS+TT treatment had the lowest IgG, and those in the FAS treatment had the highest IgG $(P<0.05$; Table 1$)$. Therefore, either IgG or $\operatorname{FPT}(0,1)$ was included as a covariate in all models.

To determine the effect of treatment on calf BW, BCS, and all other structural measurements over time, repeated-measures ANOVA (PROC MIXED) were performed. The models included each factor (fatty acid supplementation and provision of a dry teat) and cohort $(1,2)$ as fixed effects, week $(5,10)$ as a repeated measure, IgG and BW on arrival (wk 1) as a continuous covariate, and the interaction between the 2 factors (fatty acid supplementation $\times$ dry teat). Multiple covariance structures were tested, and autoregressive type
1 was selected based on best model fit using Bayesian information criterion.

To determine the effect of treatment on ADG, 3 variables were created: ADG from wk 1 to 5 (calculated as the BW difference between wk 1 and 5 divided by the total number of days between the measurements), ADG from wk 5 to 10 (calculated as the BW difference between wk 5 and 10 divided by the total number of days between the measurements), and ADG from wk 1 to 10 (calculated as the BW difference between wk 1 and 10 divided by the total number of days between the measurements). For each outcome, a generalized linear model (PROC GLM) was created that included each factor (fatty acid supplementation and dry teat) and cohort $(1,2)$ as fixed effects, IgG as a continuous covariate, and the interaction between the 2 factors (fatty acid supplementation $\times$ dry teat).

For descriptive purposes, incidence risks, defined as the proportion of calves with at least 1 incident of $\mathrm{BRD}$, diarrhea, or navel inflammation as well as any mortalities, were calculated for each treatment. A Poisson regression model (PROC GENMOD) was used to identify differences in the frequency of disease across

Table 1. Serum IgG and failure of passive transfer (FPT) of veal calves on the day after arrival (d 1) to the veal growing facility

\begin{tabular}{lcc}
\hline Treatment $^{1}$ & Serum IgG, g/L $\pm \mathrm{SD}$ & FPT, ${ }^{2} \%$ \\
\hline Control & $16.17 \pm 3.7$ & 33.9 \\
FAS & $17.95 \pm 3.7$ & 20.3 \\
TT & $13.99 \pm 3.8$ & 37.3 \\
FAS+TT & $14.29 \pm 3.7$ & 41.7 \\
\hline
\end{tabular}

${ }^{1}$ Holstein bull calves were randomly assigned to 1 of 4 treatments using a $2 \times 2$ factorial arrangement $(\mathrm{n}=60 /$ treatment $)$. Control $=$ milk replacer (MR) without fatty acid supplementation and without access to a dry teat; FAS = MR with fatty acid supplementation (NeoTec5g, Provimi, Brookville, $\mathrm{OH}$ ) and without access to a dry teat; $\mathrm{TT}=\mathrm{MR}$ without fatty acid supplementation and with access to a dry teat; $\mathrm{FAS}+\mathrm{TT}=\mathrm{MR}$ with fatty acid supplementation and with access to a dry teat.

${ }^{2}$ Defined as a serum IgG concentration of $<10 \mathrm{~g} / \mathrm{L}$. 
11 observation days (all health exams except the first exam at enrollment). The outcome of the model was the ratio of the number of observed days with disease divided by a total of $11 \mathrm{~d}$ observed. Cohort $(1,2)$ and FPT $(0,1)$ at enrollment were included in all models as a fixed effect. Health assessments from the first exam at enrollment were included in the models if $P<0.20$ at the univariable level. The final model for navel inflammation included each factor (fatty acid supplementation and dry teat), cohort and FPT as fixed effects, diarrhea and navel inflammation at enrollment as covariates, and the interaction between each factor. The final models for diarrhea and BRD included each factor (fatty acid supplementation and dry teat), cohort and FPT as fixed effects, and the interaction between the 2 factors (fatty acid supplementation $\times$ dry teat). The rate ratio and $95 \%$ confidence intervals for each disease were derived from the model using the estimate statement. Statistical significance and tendencies were declared at $P \leq 0.05$ and $P \leq 0.10$, respectively.

\section{RESULTS}

\section{Health}

Overall, $\quad 68.3 \% \quad(41 / 60), \quad 65.0 \% \quad(39 / 60), \quad 66.7 \%$ $(40 / 60)$, and $65.0 \%(39 / 60)$ of calves in the control, FAS, TT, and FAS+TT treatments had at least 1 incident of BRD. Additionally, $63.3 \%(38 / 60), 63.3 \%$ $(38 / 60), 73.3 \%(44 / 60)$, and $71.7 \%(43 / 60)$ of calves in the control, FAS, TT, and FAS+TT treatments had at least 1 incident of diarrhea. Finally, 21.7\% (13/60), $6.7 \%(4 / 60), 26.7 \%(16 / 60)$, and $18.3 \%(11 / 60)$ of calves in the control, FAS, TT, and FAS+TT treatments had at least 1 incident of navel inflammation. A total of 15 calves died during the study (cohort $1=6$, cohort $2=9$; control $=1, \mathrm{FAS}=3, \mathrm{TT}=5, \mathrm{FAS}+\mathrm{TT}$ $=6)$. There was no effect of treatment on the rate ratio of calves becoming ill with $\mathrm{BRD}$, diarrhea, or navel inflammation (Table 2).

\section{Growth}

There was no effect of fatty acid supplementation, dry teat, or their interaction on BW or BCS (Figure $2)$. There was a tendency for dry teat to decrease ADG from wk 1 to $5(P=0.08$; Figure 3$)$ but not from wk 5 to $10(P=0.60)$ or wk 1 to $10(P=0.26)$. There was a tendency for the interaction of fatty acid supplementation and dry teat to decrease ADG for wk 1 to $5(P$ $=0.096)$ but not for wk 5 to $10(P=0.26)$ or wk 1 to $10(P=0.14)$. There was no effect of fatty acid supplementation, dry teat, or their interaction on any structural growth measurements (Table 3), although there was a tendency for dry teat to reduce hip height, heart girth, and paunch girth.

\section{DISCUSSION}

The objectives of this study were to determine the effects of fatty acid supplementation and the provision of a dry teat on BRD, navel inflammation, and diarrhea in veal calves to 6 wk of age as well as growth to 10 wk of age. We found no effects of our interventions on any of the growth or health measurements collected in the study.

There was no effect of our interventions on growth, including BW, BCS, or structural measurements. Using the same fatty acid supplement provided to male calves, Hill et al. (2016) found that calves provided the supplement in MR had $13 \%$ more BW gain and $16 \%$ more hip width change over 16 wk compared with those not fed the supplement. Researchers have found similar results using a fatty acid supplement provided to calves in MR (Hill et al., 2007b) or starter (Hill et al., 2007c). Calves in our study were fed less MR than in other studies, particularly in the first few weeks of the study (220 g of MR at arrival compared with $454 \mathrm{~g}$ of MR in Hill et al., 2016), but MR allowance was gradually increased to $1,418 \mathrm{~g}$ by the time calves were $10 \mathrm{wk}$ old. Thus, the MR allowance alone was not likely a main reason for the difference in findings between our study and others. A more likely difference is the overall poor

Table 2. The effect of treatment ${ }^{1}$ on the relative risk of bovine respiratory disease, diarrhea, and navel inflammation in veal calves

\begin{tabular}{lcc}
\hline Item & $\begin{array}{c}\text { Rate ratio } \\
(95 \% \mathrm{CI})\end{array}$ & $P$-value \\
\hline Bovine respiratory disease & $1.00(0.36-2.76)$ & 0.99 \\
FAS & $1.08(0.40-2.90)$ & 0.88 \\
TT & - & 0.83 \\
FAS+TT & $1.29(0.39-4.23)$ & 0.67 \\
Diarrhea & $1.20(0.37-3.94)$ & 0.76 \\
FAS & - & 0.83 \\
TT & $0.55(0.08-3.58)$ & 0.53 \\
FAS+TT & $1.32(0.34-5.17)$ & 0.69 \\
Navel inflammation & - & 0.40 \\
FAS & - \\
TT & & \\
FAS+TT &
\end{tabular}

${ }^{1}$ Holstein bull calves were randomly assigned to 1 of 4 treatments using a $2 \times 2$ factorial arrangement $(\mathrm{n}=60 /$ treatment $)$. Control $=$ milk replacer (MR) without fatty acid supplementation and without access to a dry teat; FAS $=$ MR with fatty acid supplementation (NeoTec5g, Provimi, Brookville, $\mathrm{OH}$ ) and without access to a dry teat; $\mathrm{TT}=\mathrm{MR}$ without fatty acid supplementation and with access to a dry teat; $\mathrm{FAS}+\mathrm{TT}=\mathrm{MR}$ with fatty acid supplementation and with access to a dry teat. 
health of calves in our study compared with previous work.

There was no effect of our interventions on BRD in calves up to $6 \mathrm{wk}$ of life. To our knowledge, no other study has tested the effect of a similar fatty acid supplement on clinical signs of BRD. However, we anticipated a difference in our treatments because previous studies have demonstrated that a similar supplement improved measures of immunity in calves (Esselburn et al., 2013). For example, Esselburn et al. (2013) found that calves provided fatty acids (NeoTec4) had higher antibody titers to bovine respiratory parainfluenza-3 at 7 and 8 wk of age compared with calves not provided the supplement. Calves in our study were vaccinated for infectious bovine rhinotracheitis, parainfluenza-3, and bovine respiratory syncytial virus; however, it is unclear

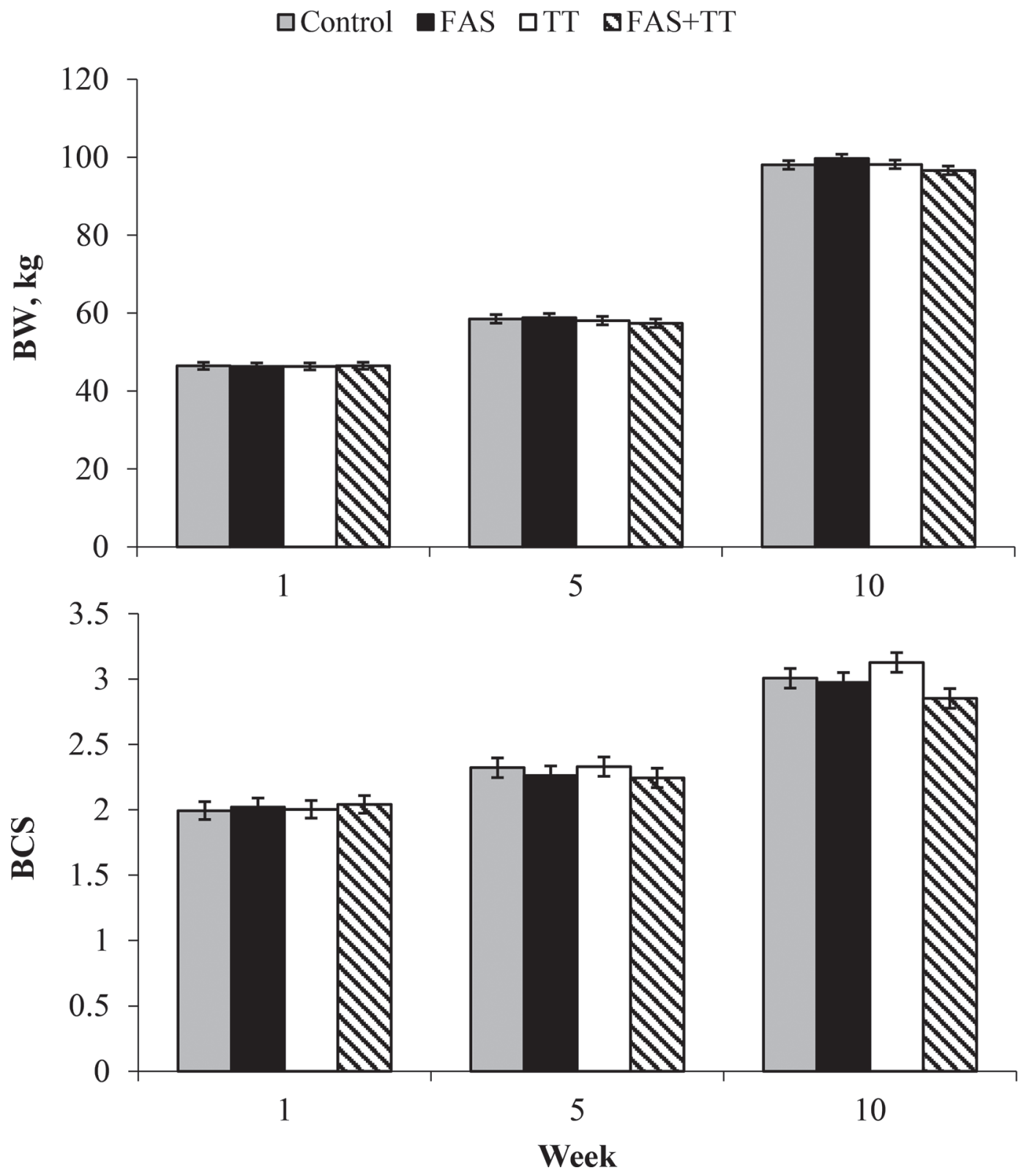

Figure 2. (A) Body weight and (B) BCS (5-point scale using 0.25-point increments, where $1=$ emaciated and $5=$ obese) of veal calves during the $10 \mathrm{wk}$ after arrival to the growing facility. Values are LSM \pm SE. Holstein bull calves were randomly assigned to 1 of 4 treatments using a $2 \times 2$ factorial arrangement $(n=60 /$ treatment $)$. Control $=$ milk replacer $(M R)$ without fatty acid supplementation and without access to a dry teat; FAS $=$ MR with fatty acid supplementation (NeoTec5g, Provimi, Brookville, $\mathrm{OH}$ ) and without access to a dry teat; TT $=$ MR without fatty acid supplementation and with access to a dry teat; FAS+TT $=$ MR with fatty acid supplementation and with access to a dry teat. 
Table 3. The effect of treatment ${ }^{1}$ on structural growth measurements (LSM and SE) in veal calves averaged across wk 5 and 10 after arrival

\begin{tabular}{|c|c|c|c|c|c|c|c|c|}
\hline \multirow[b]{2}{*}{ Variable } & \multicolumn{2}{|c|}{ No fatty acid supplement } & \multicolumn{2}{|c|}{ Fatty acid supplement } & \multirow[b]{2}{*}{$\mathrm{SE}$} & \multicolumn{3}{|c|}{$P$-value } \\
\hline & No teat & Teat & No teat & Teat & & $\begin{array}{c}\text { Fatty acid } \\
\text { supplement }\end{array}$ & Teat & Interaction \\
\hline Hip width, cm & 20.1 & 20.1 & 20.2 & 20.1 & 0.7 & 0.85 & 0.27 & 0.31 \\
\hline Heart girth, cm & 94.9 & 94.7 & 95.4 & 94.6 & 0.3 & 0.58 & 0.09 & 0.36 \\
\hline Paunch girth, cm & 98.8 & 98.5 & 99.3 & 97.9 & 0.4 & 0.99 & 0.06 & 0.22 \\
\hline
\end{tabular}

${ }^{1}$ Holstein bull calves were randomly assigned to 1 of 4 treatments using a $2 \times 2$ factorial arrangement $(\mathrm{n}=60 /$ treatment $):(1)$ milk replacer $(\mathrm{MR})$ without fatty acid supplementation and without access to a dry teat (control), (2) MR with fatty acid supplementation (NeoTec5g, Provimi, Brookville, $\mathrm{OH}$ ) and without access to a dry teat (FAS treatment), (3) MR without fatty acid supplementation and with access to a dry teat (TT treatment), and (4) MR with fatty acid supplementation and with access to a dry teat (FAS+TT treatment).

whether the fatty acid supplement influenced the antibody response in our study because this was not measured. Regardless of the efficacy of the vaccine, major risk factors for BRD in calves include insufficient space allowance, overcrowding, unsuitable temperatures, high humidity, and high ammonia concentration (Lundborg et al., 2005). In our study, the calves experienced many of these risk factors that contributed to an overall high prevalence of BRD (66\%). We were only able to detect clinical BRD using our scoring system and the visual assessment of breathing; more research is needed to determine whether fatty acids could reduce subclini- cal BRD, measured using more sophisticated methods (e.g., lung ultrasound).

There was no effect of our interventions on diarrhea in veal calves. In other studies using a similar supplement, some researchers have found reduced days with abnormal fecal scores for calves provided the supplement (Hill et al., 2007a,b, 2011b, 2016) and others have not found differences (Hill et al., 2011a). For example, Hill et al. (2016) fed a fatty acid supplement to male calves over 8 wk and found fewer abnormal fecal score days (fecal consistency score $>2$; modified from Kertz and Chester-Jones, 2004) for those provided the supple-

\section{口Control $\square$ FAS $\quad$ QTT $\mathbf{S F A S}+\mathrm{TT}$}

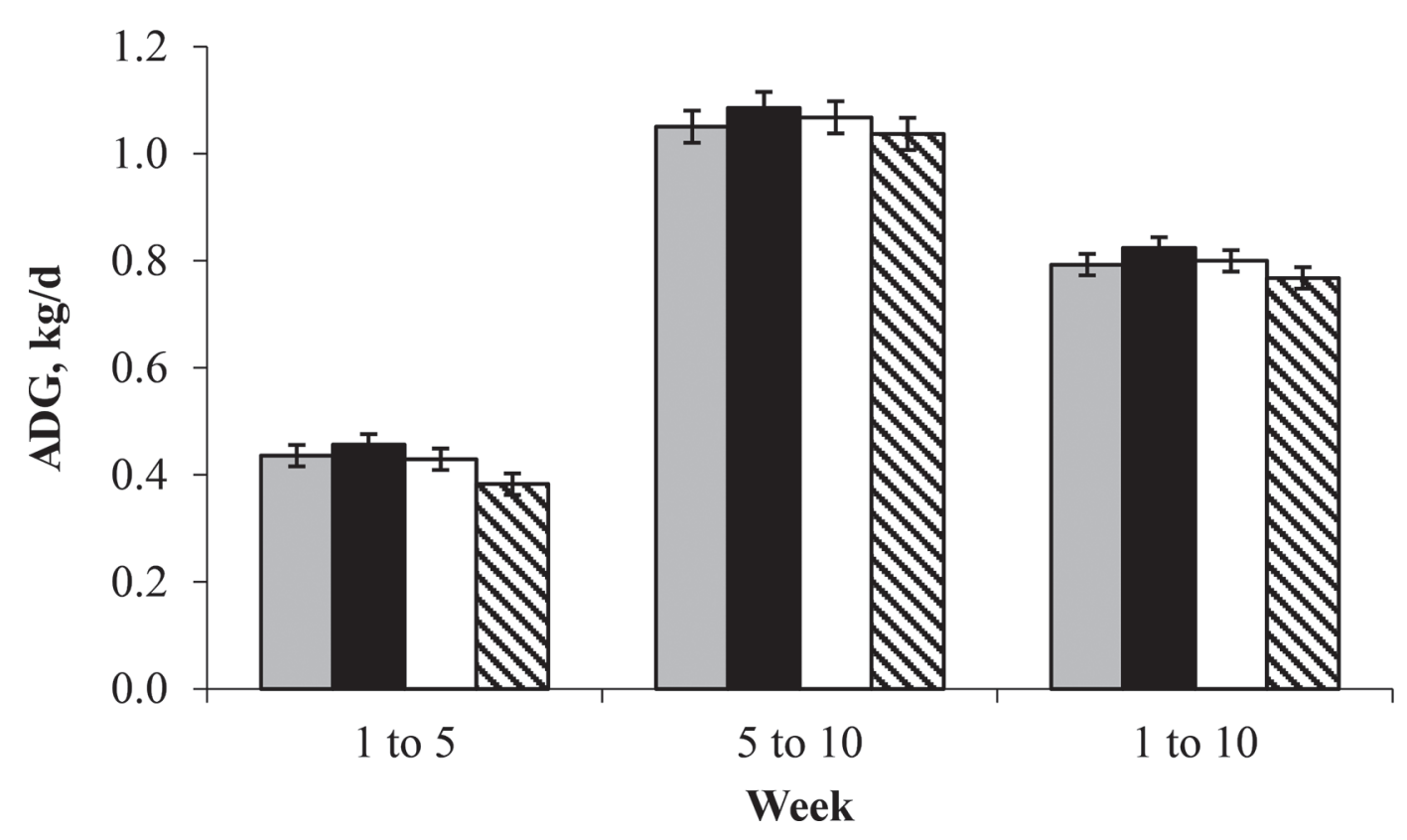

Figure 3. Average daily gain of veal calves (wk 1 to 5 , wk 1 to 10 , and wk 5 to 10 ) for the 10 wk after arrival to the growing facility. Values are LSM \pm SE. Holstein bull calves were randomly assigned to 1 of 4 treatments using a $2 \times 2$ factorial arrangement $(\mathrm{n}=60 /$ treatment) Control = milk replacer $(\mathrm{MR})$ without fatty acid supplementation and without access to a dry teat; FAS = MR with fatty acid supplementation (NeoTec5g, Provimi, Brookville, $\mathrm{OH}$ ) and without access to a dry teat; TT $=\mathrm{MR}$ without fatty acid supplementation and with access to a dry teat; FAS+TT $=\mathrm{MR}$ with fatty acid supplementation and with access to a dry teat. 
ment compared with those without the supplement. In contrast, Hill et al. (2011a) fed a fatty acid supplement (NeoTec4) to male calves for 8 wk and found no differences in abnormal fecal scores between treatments. Hill et al. (2011a) suggested that this lack of difference may have been driven by an overall lack of abnormal fecal days in the latter study (average $<1 \mathrm{~d} /$ calf). In our experiment, a high prevalence of calves had abnormal fecal scores (68\%); therefore, it may have been difficult to detect treatment differences even if they existed.

Fatty acid supplementation has been shown to influence other measures of immune function that may contribute to a reduction in enteric disease (Hill et al., 2011b). For example, Hill et al. (2011b) found that NeoTec4 reduced the inflammatory response to Pasteurella vaccination and a Salmonella toxin challenge in male calves. The authors suggested that this reduction in inflammation, in combination with other findings (improved growth and reduced diarrhea), indicates that the supplementation improved the calves' ability to respond appropriately to an enteric challenge.

There was no effect of our interventions on navel inflammation in veal calves. Although to our knowledge no research has assessed the effect of fatty acid supplementation on navel inflammation in calves, we anticipated that supplementation with fatty acids would reduce navel inflammation due to the anti-inflammatory properties of n-3 fatty acids in the formula (Hill et al., 2011b). Hill et al. (2011b) suggested that linolenic acid (an n-3 fatty acid) is likely the main factor driving the anti-inflammatory response. Indeed, inclusion of n-3 fatty acids in the diets of laboratory animals has been shown to reduce inflammation (Song et al., 2008). However, we found no differences in navel inflammation in our study.

We found no interactions between fatty acid supplementation and provision of the dry teat. We expected the provision of the teat to reduce stress in calves by allowing the calves to better satiate their strong motivation to suckle (Veissier et al., 2002). We also expected that calves with a dry teat may have a lower exposure to environmental pathogens due to reduced nibbling on pen fixtures. In a similar study, Veissier et al. (2002) provided bucket-fed veal calves with access to a dry teat and found that calves provided the teat spent less time nibbling on pen fixtures and tended to have a shortened latency to lie down after a milk meal compared with calves without a teat. In addition, the provision of a dry teat has been found to influence digestion; for example, de Passillé et al. (1993) found that concentrations of both insulin and cholecystokinin in the blood after a milk meal were higher if calves were given a dry teat after the meal compared with those not provided a teat. As veal calves move more to pair and group housing, more research is encouraged to create better environments for calves to satiate their motivation to suckle, such as increased milk allowance (Jung and Lidfors, 2001), provision of MR through a nipple (Mees and Metz, 1984), and the provision of hay as supplemental feed (Haley et al., 1998). More research measuring the usage of dry teats for veal calves is also encouraged, as this is likely highly variable and dependent on the calf.

A main limitation of the study was that for practical reasons we could not measure disease outcomes daily and could not measure BW weekly, although these frequencies may be preferable. However, unlike some experiments using controlled experimental conditions (e.g., Hill et al., 2011a), our trial was conducted in a field setting where it would not be practical to measure data outcomes so frequently. We still feel confident in our results; based on previous literature, these sampling times are consistent with others that have measured disease and growth in dairy and veal calves using field trials (McGuirk, 2008; McGuirk and Peek, 2014; Pempek et al., 2018).

A second limitation of the study is the high prevalence of disease in our sample (66\% of calves had BRD and $68 \%$ of calves had diarrhea at least once). This high rate of disease may have contributed to our inability to detect treatment differences for disease and growth measurements. Compared with other studies that have tested the effect of fatty acid supplementation on calf growth and immunity (Hill et al., 2007a,b, 2016), our population was more challenged due to a high rate of FPT (33.3\%) when they first arrived at the grower. Veal calves also face several unique challenges compared with dairy calves, including stressors associated with transportation, commingling, poor ventilation, and barren housing. For example, Hill et al. (2016) sourced calves from a single location and housed calves individually in a naturally ventilated nursery barn with deep straw bedding. For our experiment, calves were sourced from multiple dairy farms and were housed in a mechanically ventilated barn on slatted floors. We suggest that improvements to housing and management are first needed before evaluating the effect of specific interventions such as a nutritional supplementation and provision of a teat.

\section{CONCLUSIONS}

We found no effects of a fatty acid supplement and a dry teat provided to veal calves on growth or health measurements. More research on improvements to the housing and management of veal calves on the home 
dairy and at the veal grower is needed before testing the effect of specific nutritional supplements on growth and disease.

\section{ACKNOWLEDGMENTS}

This study was partially funded by Provimi (Brookville, $\mathrm{OH}$ ). We are very grateful to Atlantic Veal and Lamb LLC (New York, NY) for the use of their calves for this study and to their farm staff for helping with sampling and data collection. We thank Lindsey Hulbert and Luke Ruiz from Kansas State University (Manhattan) for providing the dry teats for the study. We also thank Meghan Studds, Dana Sorter, and Brad Hogshead from The Ohio State University (Columbus), without whom this project would not have been possible. The authors have not stated any conflicts of interest.

\section{REFERENCES}

Bähler, C., A. Steiner, A. Luginbühl, A. Ewy, H. Posthaus, D. Strabel, T. Kaufmann, and G. Regula. 2012. Risk factors for death and unwanted early slaughter in Swiss veal calves kept at a specific animal welfare standard. Res. Vet. Sci. 92:162-168. https://doi .org/10.1016/j.rvsc.2010.10.009.

Brscic, M., L. Heutinck, M. Wolthuis-Fillerup, N. Stockhofe, B. Engel, E. Visser, F. Gottardo, E. Bokkers, B. Lensink, G. Cozzi, and C. Van Reenen. 2011. Prevalence of gastrointestinal disorders recorded at postmortem inspection in white veal calves and associated risk factors. J. Dairy Sci. 94:853-863. https://doi.org/10.3168/jds .2010-3480.

Brscic, M., H. Leruste, L. Heutinck, E. Bokkers, M. Wolthuis-Fillerup, N. Stockhofe, F. Gottardo, B. Lensink, G. Cozzi, and C. Van Reenen. 2012. Prevalence of respiratory disorders in veal calves and potential risk factors. J. Dairy Sci. 95:2753-2764. https://doi.org/ 10.3168/jds.2011-4699.

de Passillé, A. M. 2001. Sucking motivation and related problems in calves. Appl. Anim. Behav. Sci. 72:175-187. https://doi.org/10 .1016/S0168-1591(01)00108-3.

de Passillé, A. M., R. Christopherson, and J. Rushen. 1993. Nonnutritive sucking by the calf and postprandial secretion of insulin, CCK, and gastrin. Physiol. Behav. 54:1069-1073. https://doi.org/ 10.1016/0031-9384(93)90326-B.

de Passillé, A. M., J. Rushen, and M. Janzen. 1997. Some aspects of milk that elicit non-nutritive sucking in the calf. Appl. Anim. Behav. Sci. 53:167-173. https://doi.org/10.1016/S0168-1591(96)01161-6.

Esselburn, K. M., K. O'Diam, T. Hill, H. Bateman II, J. Aldrich, R. Schlotterbeck, and K. Daniels. 2013. Intake of specific fatty acids and fat alters growth, health, and titers following vaccination in dairy calves. J. Dairy Sci. 96:5826-5835. https://doi.org/10.3168/ jds.2013-6608.

Fecteau, G., J. Pare, D. C. Van Metre, B. P. Smith, C. A. Holmberg, W. Guterbock, and S. Jang. 1997. Use of a clinical sepsis score for predicting bacteremia in neonatal dairy calves on a calf rearing farm. Can. Vet. J. 38:101-104.

Haley, D. B., J. Rushen, I. Duncan, T. Widowski, and A. de Passillé. 1998. Effects of resistance to milk flow and the provision of hay on nonnutritive sucking by dairy calves. J. Dairy Sci. 81:2165-2172. https://doi.org/10.3168/jds.S0022-0302(98)75794-7.

Hill, T., J. Aldrich, R. Schlotterbeck, and H. Bateman II. 2007a. Amino acids, fatty acids, and fat sources for calf milk replacers. Prof. Anim. Sci. 23:401-408. https://doi.org/10.15232/S1080 -7446(15)30995-5.
Hill, T., J. Aldrich, R. Schlotterbeck, and H. Bateman II. 2007b. Effects of changing the fat and fatty acid composition of milk replacers fed to neonatal calves. Prof. Anim. Sci. 23:135-143. https://doi .org/10.15232/S1080-7446(15)30953-0.

Hill, T., J. Aldrich, R. Schlotterbeck, and H. Bateman II. 2007c. Effects of changing the fatty acid composition of calf starters. Prof. Anim. Sci. 23:665-671. https://doi.org/10.15232/S1080 -7446(15)31038-X.

Hill, T., H. Bateman II, J. Aldrich, and R. Schlotterbeck. 2011a. Effect of various fatty acids on dairy calf performance. Prof. Anim. Sci. 27:167-175. https://doi.org/10.15232/S1080-7446(15)30470-8.

Hill, T. M., J. Quigley, F. Suarez-Mena, H. Bateman II, and R. Schlotterbeck. 2016. Effect of milk replacer feeding rate and functional fatty acids on dairy calf performance and digestion of nutrients. J. Dairy Sci. 99:6352-6361. https://doi.org/10.3168/jds.2015-10812.

Hill, T. M., M. Vandehaar, L. Sordillo, D. Catherman, H. Bateman II, and R. Schlotterbeck. 2011b. Fatty acid intake alters growth and immunity in milk-fed calves. J. Dairy Sci. 94:3936-3948. https:// doi.org/10.3168/jds.2010-3935.

Jung, J., and L. Lidfors. 2001. Effects of amount of milk, milk flow and access to a rubber teat on cross-sucking and non-nutritive sucking in dairy calves. Appl. Anim. Behav. Sci. 72:201-213. https://doi .org/10.1016/S0168-1591(01)00110-1.

Kertz, A. F., and H. Chester-Jones. 2004. Invited review: Guidelines for measuring and reporting calf and heifer experimental data. J. Dairy Sci. 87:3577-3580. https://doi.org/10.3168/jds.S0022 -0302(04)73495-5.

Love, W. J., T. Lehenbauer, P. Kass, A. Van Eenennaam, and S. Aly. 2014. Development of a novel clinical scoring system for on-farm diagnosis of bovine respiratory disease in pre-weaned dairy calves. PeerJ 2:e238. https://doi.org/10.7717/peerj.238.

Love, W. J., T. Lehenbauer, A. Van Eenennaam, C. Drake, P. Kass, T. Farver, and S. Aly. 2016. Sensitivity and specificity of on-farm scoring systems and nasal culture to detect bovine respiratory disease complex in preweaned dairy calves. J. Vet. Diagn. Invest. 28:119-128. https://doi.org/10.1177/1040638715626204.

Lundborg, G. K., E. Svensson, and P. Oltenacu. 2005. Herd-level risk factors for infectious diseases in Swedish dairy calves aged 0-90 days. Prev. Vet. Med. 68:123-143. https://doi.org/10.1016/j .prevetmed.2004.11.014.

Mancini, G., A. Carbonara, and J. Heremans. 1965. Immunochemical quantitation of antigens by single radial immunodiffusion. Immunochemistry 2:235-254. https://doi.org/10.1016/0019 $-2791(65) 90004-2$.

McGuirk, S. M. 2008. Disease management of dairy calves and heifers. Vet. Clin. North Am. Food Anim. Pract. 24:139-153. https://doi .org/10.1016/j.cvfa.2007.10.003.

McGuirk, S. M., and S. F. Peek. 2014. Timely diagnosis of dairy calf respiratory disease using a standardized scoring system. Anim. Health Res. Rev. 15:145-147. https://doi.org/10.1017/ S1466252314000267.

Mees, A. M. F., and J. H. M. Metz. 1984. Onderzoek omtrent de zuigbehoefte van kalveren. Bedrijfsontwikkeling 15:131-134.

Pardon, B., J. Alliët, R. Boone, S. Roelandt, B. Valgaeren, and P. Deprez. 2015. Prediction of respiratory disease and diarrhea in veal calves based on immunoglobulin levels and the serostatus for respiratory pathogens measured at arrival. Prev. Vet. Med. 120:169-176. https://doi.org/10.1016/j.prevetmed.2015.04.009.

Pardon, B., K. De Bleecker, M. Hostens, J. Callens, J. Dewulf, and P. Deprez. 2012. Longitudinal study on morbidity and mortality in white veal calves in Belgium. BMC Vet. Res. 8:26. https://doi.org/ 10.1186/1746-6148-8-26.

Pardon, B., M. Hostens, L. Duchateau, J. Dewulf, K. De Bleecker, and P. Deprez. 2013. Impact of respiratory disease, diarrhea, otitis and arthritis on mortality and carcass traits in white veal calves. BMC Vet. Res. 9:79. https://doi.org/10.1186/1746-6148-9-79.

Pempek, J. A., E. Holder, K. Proudfoot, M. Masterson, and G. Habing. 2018. Short communication: Investigation of antibiotic alternatives to improve health and growth of veal calves. J. Dairy Sci. 101:4473-4478. https://doi.org/10.3168/jds.2017-14055. 
Pempek, J., D. Trearchis, M. Masterson, G. Habing, and K. Proudfoot. 2017. Veal calf health on the day of arrival at growers in Ohio. J. Anim. Sci. 95:3863-3872. https://doi.org/10.2527/jas2017 .1642 .

Renaud, D. L., T. Duffield, S. Leblanc, S. Ferguson, D. Haley, and D. Kelton. 2018a. Risk factors associated with mortality at a milkfed veal calf facility: A prospective cohort study. J. Dairy Sci. 101:2659-2668. https://doi.org/10.3168/jds.2017-13581.

Renaud, D. L., D. Kelton, S. Leblanc, D. Haley, and T. Duffield. 2018b. Calf management risk factors on dairy farms associated with male calf mortality on veal farms. J. Dairy Sci. 101:17851794. https://doi.org/10.3168/jds.2017-13578.

Renaud, D. L., M. Overton, D. Kelton, S. Leblanc, K. Dhuyvetter, and T. Duffield. 2018c. Effect of health status evaluated at arrival on growth in milk-fed veal calves: A prospective single cohort study. J. Dairy Sci. 101:10383-10390. https://doi.org/10.3168/jds.2018 $-14960$.

Rushen, J., and A. de Passillé. 1995. The motivation of non-nutritive sucking in calves, Bos taurus. Anim. Behav. 49:1503-1510. https:/ /doi.org/10.1016/0003-3472(95)90071-3.

Song, C., M. Manku, and D. Horrobin. 2008. Long-chain polyunsaturated fatty acids modulate interleukin- $1 \beta$-induced changes in behavior, monoaminergic neurotransmitters, and brain inflammation in rats. J. Nutr. 138:954-963. https://doi.org/10.1093/jn/138.5 .954.
Veissier, I., A. de Passillé, G. Després, J. Rushen, I. Charpentier, A. Ramirez de la Fe, and P. Pradel. 2002. Does nutritive and nonnutritive sucking reduce other oral behaviors and stimulate rest in calves? J. Anim. Sci. 80:2574-2587. https://doi.org/10.2527/2002 $.80102574 x$

Wildman, E., G. Jones, P. Wagner, R. Boman, H. Troutt Jr., and T. Lesch. 1982. A dairy cow body condition scoring system and its relationship to selected production characteristics. J. Dairy Sci 65:495-501. https://doi.org/10.3168/jds.S0022-0302(82)82223-6.

Wilson, L. L., J. Smith, D. Smith, D. Swanson, T. Drake, D. Wolfgang, and E. Wheeler. 2000. Characteristics of veal calves upon arrival, at 28 and 84 days, and at end of the production cycle. J. Dairy Sci. 83:843-854. https://doi.org/10.3168/jds.S0022-0302(00)74948-4.

\section{ORCIDS}

L. L. Deikun () https://orcid.org/0000-0002-5143-6571

G. G. Habing (1) https://orcid.org/0000-0002-0855-7650

J. D. Quigley @ https://orcid.org/0000-0001-8400-8963

K. L. Proudfoot @ https://orcid.org/0000-0001-5877-2431 